\title{
El carácter analítico y político del concepto de colonialismo interno de Pablo González Casanova
}

\author{
Jaime Torres Guillén
}

El artículo se centra en el reconocimiento al trabajo de Pablo González Casanova, en especial su contribución para esclarecer fenómenos de exclusión social en contextos indígenas con el uso de una de sus categorías clave: el colonialismo interno. Se muestra la génesis del concepto, los problemas teóricos a su alrededor y la actualización que sufrió su uso con el paso del tiempo. El objetivo radica en dar razón del carácter analítico y político del concepto, así como de su vigencia para alumbrar problemas sociales relacionados con el fenómeno del colonialismo.

PALABRAS CLAVE: Pablo González Casanova, colonialismo interno, colonialismo, colonialismo global, explotación, democracia universal, resistencia política

\section{The Analytical and Political Character of Internal Colonialism Concept of Pablo González Casanova}

The article focuses on the recognition of Pablo González Casanova work, especially his contribution to elucidating phenomena of social exclusion in indigenous contexts using one of his key concepts: internal colonialism. The paper shows the genesis of the concept, the theoretical problems around it, and the update the use of the concept have undergone through time. We aim to explain the analytical and political nature of the concept, as well as its validity to illuminate social problems related to colonialism phenomenon.

KEYWORDS: Pablo González Casanova, internal colonialism, colonialism, global colonialism, exploitation, universal democracy, political resistance 


\section{INTRODUCCIÓN}

$\mathrm{P}$ ablo González Casanova incorporó el concepto de "colonialismo interno" al campo de las ciencias sociales de la década de 1960 en América Latina, en particular en los estudios sobre los procesos de exclusión y agravio en contextos indígenas. Sobre este punto, poco se ha reconocido el trabajo científico y político de González Casanova. En buena medida la noción de "colonialismo interno" ha pasado inadvertida entre intelectuales y científicos sociales extranjeros o latinoamericanos. Florencia E. Mallon es una excepción. La historiadora expresó alguna vez que los latinoamericanistas ubicados en la academia de Estados Unidos, a la distancia de los mundos intelectuales del sur, perdían de vista la ciencia y los conceptos que se desarrollaban en el continente. Para ella, una de las tradiciones latinoamericanas que ayudan a entender el fenómeno del colonialismo es precisamente La democracia en México, de González Casanova (1978). Florencia

E. Mallon aceptó que ella misma había rechazado el concepto de "colonialismo interno" porque lo relacionaba con "las formas más rígidas y estructurales" de la teoría de la dependencia (Mallon, 2003: 68). Después admitió que el concepto era significativo al aplicarlo "en el contexto de la nueva militancia indígena de los años ochenta y noventa" del siglo pasado, por lo que le parecía relevante rescatar el trabajo pionero de González Casanova. ${ }^{1}$

Es comprensible que durante el tiempo que González Casanova teorizó sobre el colonialismo interno la gran mayoría de los intelectuales que ahora insisten en la descolonización del saber para pensar nuestra historia estuvieran influidos por la historiografía de corte positivista, ya fuera de la línea marxista o liberal. No tomaron en cuenta el

\footnotetext{
${ }^{1}$ Aun con esta aceptación de olvido por parte de la historiadora, hay quienes en esa misma disciplina ignoran el aporte de González Casanova sobre fenómenos de colonialismo. Romana Falcón, por ejemplo, le otorga el crédito del concepto de "colonialismo interno" a Guillermo Bonfil Batalla (Falcón, 2002: 12).
}

concepto del sociólogo mexicano quizá por considerarlo incompatible con su enfoque teórico. Sin embargo, lo que no es justificable es que se ignore que los términos de "colonialidad del saber" o “pensamiento descolonial”, por ejemplo, son posteriores al del colonialismo interno y hunden su raíz en él. Para el caso que nos incumbe, como lo ha hecho saber Silvia Rivera Cusicanqui:

el trabajo de Pablo González Casanova, casi nunca citado, sobre "el colonialismo interno" se publicó en 1969 cuando Walter Mignolo y Aníbal Quijano estaban todavía militando en el marxismo positivista y en la visión lineal de la historia (Rivera, 2010: 66).

A la fecha, ni Mignolo ni Quijano han reivindicado el trabajo de González Casanova. Tampoco han reconocido que lo perdieron de vista en algún momento de su trayectoria académica. Rivera Cusicanqui narra una anécdota que concuerda con lo dicho hasta aquí:

Escribí hace un tiempo una crítica política de la izquierda boliviana para un seminario que organizó una fundación académica en México. El artículo titulado "Acerca de los problemas de las llamadas izquierdas" intentaba criticar el modo en que las elites de la izquierda marxista en Bolivia, por su visión ilustrada y positivista, habían obviado la arena de la identidad india y los problemas de la descolonización, aplicando un análisis reduccionista y formulístico que les permitía reproducir cómodamente la dominación cultural que ejercían por su origen de clase y por su dominio de la lengua legítima y el pensamiento occidental. Era obvio que, para hacerlo, usaban discursos encubridores, y se autoproclamaban voceros e intérpretes de las demandas de los pueblos indígenas. $\mathrm{Mi}$ artículo usaba profusamente la noción de "colonialismo interno" para analizar este complejo de superioridad de los intelectuales de clase media respecto de sus pares indígenas y todas las derivaciones políticas de este hecho. Lo cierto es que los editores de la revista en inglés me sugirieron que corrigiera mis fuentes. Señalaron que debía citar la idea de la "colonialidad del saber" de Aníbal Quijano, para hacer publicable mi texto ante una audiencia que desconocía por 
completo los aportes de González Casanova y del Taller de Historia Oral Andina (Rivera, 2010: 66-67).

El concepto de "colonialismo interno" no es patrimonio exclusivo de la veta intelectual de González Casanova, de hecho se ha usado en diferentes contextos y bajo líneas metodológicas diversas (Hicks, 2004; Drakakis-Smith y Wyn, 1983). Por ejemplo, Michael Hechter (1975), en la década de los años setenta del siglo anterior, lo aplicó en los escenarios donde irlandeses, escoceses y galeses seguían manteniendo una posición inferior, desigual y marginal frente a los sectores dominantes británicos a pesar del desarrollo nacional y la industrialización de la región. Respecto de Brasil, Yves Chaloult (1978) argumenta que la independencia política del país no fue suficiente para acabar con el colonialismo. Con la desaparición de la dominación directa de los extranjeros sobre los nativos emergía de manera extraña la dominación y la explotación de los nativos por otros nativos. También, como veremos en este artículo, contemporáneos de González Casanova analizaron el concepto desde ópticas críticas para su utilización en los contextos de la llamada dependencia latinoamericana, como Rodolfo Stavenhagen y André Gunder Frank.

Para el caso que nos ocupa, puede afirmarse que no existe un trabajo que dé testimonio exclusivamente de la génesis, el desarrollo, la crisis y el replanteamiento del concepto de "colonialismo interno" usado por Pablo González Casanova para pensar América Latina. Aunque es común encontrarse hoy a historiadores que sostienen que después de la Conquista el dominio español sobre los indígenas en México fue sustituido por un dominio interno, criollo y mestizo, con características muy parecidas a la época anterior a la Independencia, ${ }^{2}$ ninguno de ellos menciona la aportación de

\footnotetext{
2 Consúltense Huerta (1976), Reina (1986), Mirafuentes (1989),
} Katz (1990) y Van Young (2006).
González Casanova sobre el colonialismo interno. Derivado de esto, el interés de este artículo se centra en el reconocimiento al trabajo de Pablo González Casanova, en especial en el rubro de uno de sus conceptos base: el colonialismo interno. El objetivo es mostrar el carácter analítico y político del concepto, así como su vigencia en ambos campos. Por una parte, se muestra la génesis del concepto en este autor; por otra, se iluminan los problemas teóricos y la actualización que sufrió la categoría con el paso del tiempo.

Para tal efecto esta exposición se dividirá en cuatro partes. En la primera se trata el origen del concepto en la obra de González Casanova, se describe la problematización analítica que se desprende una vez que se intenta explicar por qué en las sociedades del llamado "Tercer Mundo" el colonialismo permanecía aun después de la independencia política de las naciones. En la segunda parte se alude a las críticas de que fue objeto el concepto en dos aspectos: el primero, a propósito del tema de las sociedades duales que González Casanova incluyó en sus primeros escritos sobre colonialismo interno; el segundo, el supuesto reemplazo del concepto de "lucha de clases" por el de "colonialismo interno", aporte de Rodolfo Stavenhagen y André Gunder Frank, quienes aparecen como los principales interlocutores de González Casanova. El apartado expone la manera en que la crítica es fundada en el primer aspecto y falsa en el segundo.

La redefinición por parte de González Casanova y las reificaciones de las que el concepto de "colonialismo interno" fue objeto integran el contenido del tercer apartado. Se describe la desvinculación que sufrió el mismo respecto de otros, como el de clases sociales o el de la lucha por el poder efectivo de un Estado-nación multiétnico, así como el hecho de que algunos militantes de izquierda y partidos comunistas convirtieran el concepto en un tabú. En la cuarta y última parte haremos mención general del carácter político del concepto de "colonialismo interno" conectado con lo que González Casanova denomina "colonialismo global" y "democracia 
universal". La idea es demostrar que el concepto no sólo es útil como categoría analítica porque da razón de fenómenos relacionados con la exclusión cultural y la explotación económica, sino que como concepto político permite organizar socialmente la resistencia de acuerdo con las estructuras de dominio, una vez que los sujetos agraviados descubren las formas en que éstas actúan.

\section{LA PRIMERA NOCIÓN: EL COLONIALISMO INTERNO EXPLICADO A PARTIR DE LAS RELACIONES SOCIALES POSTERIORES A LA INDEPENDENCIA}

Hacia finales de los años sesenta del siglo pasado, Pablo González Casanova incorporó en Sociología de la explotación (1969) un artículo casi íntegro que había publicado en 1963 con el título "Sociedad plural, colonialismo interno y desarrollo" (González, 1963a). El objeto de ese trabajo era precisar el carác-

ter relativamente intercambiable de las nociones de "colonialismo" y "estructura colonial", con énfasis en el colonialismo como un fenómeno interno. Intentaba mostrar lo transnacional de este fenómeno, sobre todo en los problemas de desarrollo a los que se enfrentaban las nuevas naciones de África, Asia y América Latina (González, 1963a: 15). El autor estaba persuadido de que el concepto de "colonialismo interno" sólo había podido surgir a raíz de observar que los movimientos de independencia de las antiguas colonias, en sus experiencias de autonomía frente a lo extranjero, provocaban la aparición de nuevas relaciones sociales a propósito de las ideas de independencia y desarrollo. Al tratar el concepto, González Casanova quería probar su capacidad explicativa: "su potencial de explicación sociológica del subdesarrollo y de explicación operacional de los problemas de las sociedades subdesarrolladas" (González, 1963a: 17). Se acerca al problema al tipificar el colonialismo como un fenómeno integral que podía observarse en lo internacional y en lo interno de una nación.
González Casanova se cuestionaba si en realidad era un nuevo concepto para el estudio del desarrollo. Si lo era, acaso fuera preciso especificar que registrase fenómenos diferentes a los que se recogían con los conceptos de "ciudad", "campo", "clases sociales" o "estratificación". La cuestión era saber si servía para explicar los problemas de las sociedades subdesarrolladas. Como se ha dicho, la categoría podía usarse, por un lado, al cambiar el fenómeno del colonialismo de categoría internacional a categoría interna, y por otro, al aplicarlo a una nación que transitaba de una etapa de reforma agraria a una de industrialización, de construcción de la infraestructura, hacia un amplio proceso de movilización de la población que participaba del desarrollo. También fue en esa década cuando González Casanova esbozó el fenómeno del colonialismo interno y su comportamiento en el México contemporáneo. Para ello presentó las características típicas del colonialismo en general. En el contexto político de la época se decía que una colonia era: 1) un territorio sin gobierno propio; 2) que se encuentra en una situación de desigualdad respecto de la metrópoli donde los habitantes sí se gobiernan a sí mismos; 3) que la administración y la responsabilidad de la administración conciernen al Estado que la domina; 4) que sus habitantes no participan en la elección de los más altos cuerpos administrativos, es decir, que sus dirigentes son designados por el país dominante; 5) que los derechos de sus habitantes, su situación económica y sus privilegios sociales son regulados por otro Estado; 6) que esta situación no corresponde a lazos naturales, sino artificiales, producto de una conquista, de una concesión internacional, y 7) que sus habitantes pertenecen a una raza y a una cultura distintas de las dominantes y que hablan una lengua también distinta (González, 1963a: 18).

Sin embargo, para González Casanova esta definición era insuficiente porque se centraba sólo en aspectos jurídicos y políticos de manera formal y olvidaba fenómenos como el neocolonialismo o los cambios que sufría la misma estructura colonial. La 
observación del sociólogo mexicano era: "Siempre que hay una colonia se da, en efecto, una condición de monopolio en la explotación de los recursos naturales, del trabajo, del mercado de importación y exportación, de las inversiones, de los ingresos fiscales" (González, 1963a: 19). Este proceso de monopolio se extiende a otros rubros, como la cultura y la comunicación. La forma de comunicarse, de expresarse y de dialogar con otras culturas se realiza por medio de la metrópoli. El dominio económico y cultural se refuerza mediante el dominio militar, político y administrativo. De esta manera, "la colonia adquiere las características de una economía complementaria de la metrópoli, se integra a la economía de la metrópoli” (González, 1969: 233), y por tanto se convierte en dependiente económico, sus relaciones son desiguales, tiene nula capacidad de negociación, es un lugar ideal para la explotación de mano de obra y para el monopolio de los recursos, y los sistemas represivos son sumamente violentos.

El proceso que comienza con las desigualdades económicas, políticas o culturales entre la metrópoli y la colonia se continúa en la transferencia de una desigualdad interna entre los metropolitanos y los indígenas: desigualdades raciales, de castas, de fueros, religiosas, rurales y urbanas, de clases. Para nuestro autor, esta desigualdad tenía importancia porque con ella se comprendía no sólo la base de una sociedad colonial, sino la dinámica de lo que en ese entonces se denominaban "sociedades duales" o "plurales". González Casanova estaba de acuerdo con Jacques Lambert (1978) en cuanto a la idea de que la sociedad dual era producto del encuentro de una sociedad atrasada con una tecnológicamente avanzada. En la imagen de esta representación sociológica aparecía el europeo evolucionado y el indígena arcaico. González Casanova decía:

en las colonias se combinan y coexisten las antiguas relaciones de tipo esclavista y feudal y las de la empresa capitalista, industrial, con trabajo asalariado. La heterogeneidad técnica, institucional y cultural coincide con una estructura en que las relaciones de dominio y explotación son relaciones entre grupos heterogéneos, culturalmente distintos (González, 1969: 236).

En este sentido, las implicaciones políticas y psicológicas en los colonizados eran considerables. Como las humillaciones y agravios redundaban en la autonomía y moral de los oprimidos, con ello se impedía su emancipación. Ahora bien, González Casanova observaba que todas estas características típicas del colonialismo seguían operando aun en medio de las independencias nacionalistas de manera internacional e interna. Hacia la década de 1970 definió el colonialismo interno como:

\begin{abstract}
una estructura de relaciones sociales de dominio y explotación entre grupos culturales heterogéneos, distintos. Si alguna diferencia específica tiene respecto de otras relaciones de dominio y explotación (ciudadcampo, clases sociales) es la heterogeneidad cultural que históricamente produce la conquista de unos pueblos por otros, y que permite hablar no sólo de diferencias culturales (que existen entre la población urbana y rural y en las clases sociales) sino de diferencias de civilización (González, 1969: 240).
\end{abstract}

Desde esta perspectiva, el concepto de "colonialismo interno" ofrece potencialidad explicativa para fenómenos derivados del conflicto entre dos culturas, de los cuales se desprenden, por ejemplo, la discriminación, la exclusión y la invisibilización social. El concepto también permite aclarar aspectos de esta relación social asimétrica que un análisis de clases no alcanza a determinar, como comprender que en una estructura colonial la relación de dominio y explotación se ejerce no de propietario a trabajador, sino de "una población (con sus distintas clases, propietarios, trabajadores) por otra población que también tiene distintas clases (propietarios y trabajadores)" (González, 1969: 241). Entonces el colonialismo interno como categoría analítica podría explicar por qué en las sociedades duales el colonialismo permanecía aun después de la independencia 
política de las naciones. Esto es, el concepto se convierte en una pista para responder la siguiente interrogante: ¿por qué a pesar de transformaciones sociales significativas en el campo, la ciudad, la industria, la educación y la estratificación social, producto de procesos de independencia política, en los pueblos de América Latina la estructura colonial queda intacta?

La problematización es sugerente porque el concepto podría contribuir a iluminar los límites políticos por los que han atravesado los Estados latinoamericanos para orientar a los miembros de las nuevas sociedades independientes para transitar hacia sistemas institucionales de igualdad, participación e inclusión democrática. En este sentido, la categoría de colonialismo interno contiene también un valor político que otorga elementos de juicio a los movimientos sociales que luchan por la democracia, la autonomía o el socialismo, porque integran el tema de la descolonización a sus programas de acción. Podríamos decir que desde su raíz el concepto tenía amplias posibilidades explicativas acerca de los fenómenos de exclusión, invisibilización y agravio moral de los grupos subalternos, en particular los indígenas. Pero en aquellos años los científicos sociales, los intelectuales y los militantes no se habían enterado.

\section{LA CRÍTICA AL CONCEPTO DE SOCIEDAD DUAL. UN CUESTIONAMIENTO A LA PERSPECTIVA DE PABLO GONZÁLEZ CASANOVA SOBRE EL COLONIALISMO INTERNO}

La postura de Pablo González Casanova sobre el tema de las sociedades duales fue cuestionada en América Latina primero por Rodolfo Stavenhagen

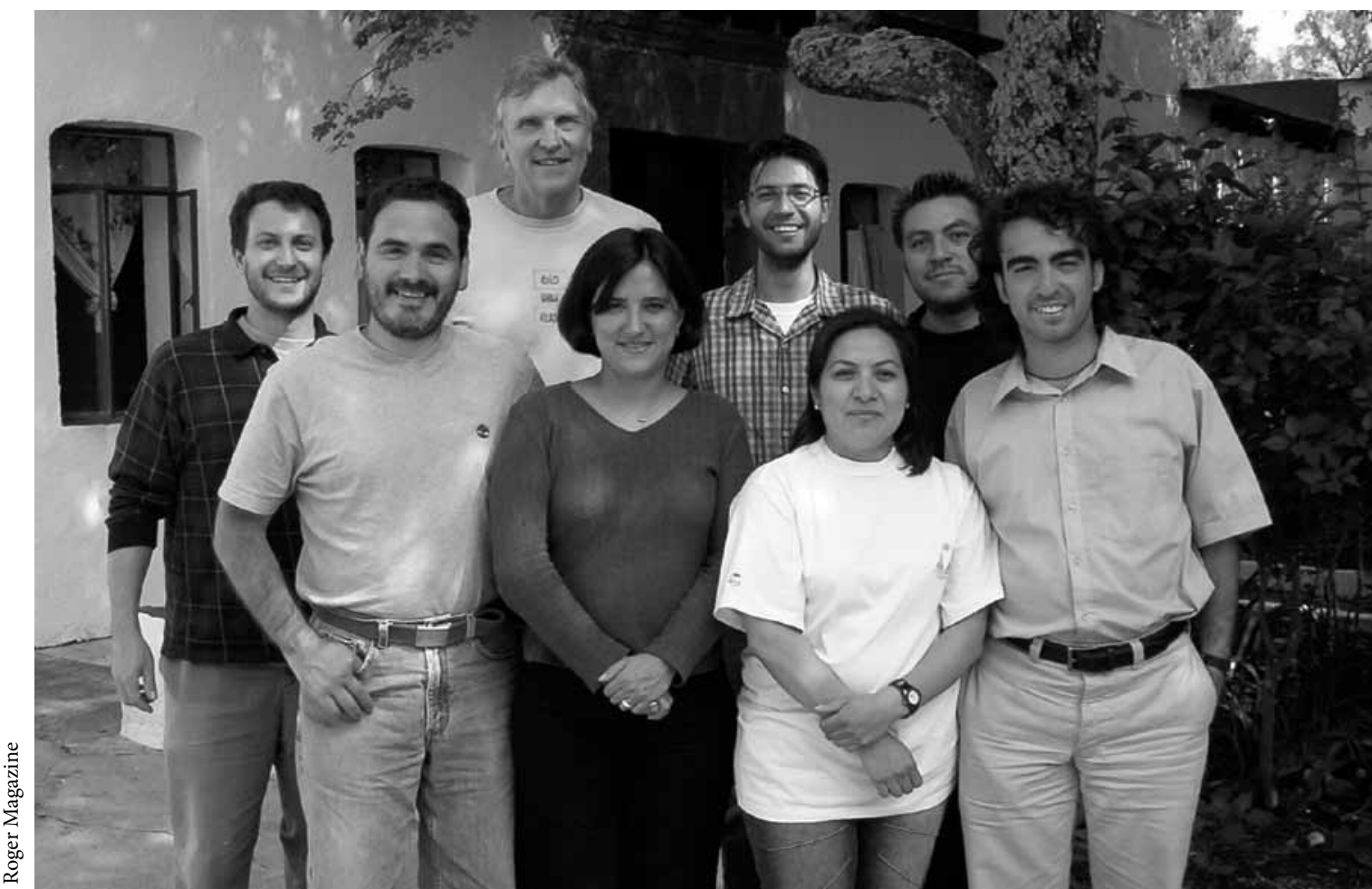

Práctica de campo en la Casa "José de Acosta”, 2003. 
y después por André Gunder Frank. El primero lo hizo en su famoso ensayo "Siete tesis equivocadas sobre América Latina” (Stavenhagen, 1981) aparecido los días 25 y 26 de junio de 1965 en el periódico El Día. La crítica se centraba en la confusión del término "dual" al aplicarlo a las diferencias sociales, culturales o económicas que prevalecían en el continente, pues se tenía en mente con ello que había dos sociedades, una capitalista y la otra feudal, o una moderna y otra arcaica. El empleo del concepto "sociedad dual" no era justificado para Stavenhagen debido a que ambos polos eran resultado de un único proceso histórico. Es decir, las relaciones entre regiones arcaicas y modernas, o capitalistas y semicapitalistas, representaban el funcionamiento de una sola sociedad global (Stavenhagen, 1981: 17). El asunto no era entonces la existencia de dos sociedades, sino la relación de esas dos realidades en un mismo sistema: el capitalista. Para Stavenhagen el término más apropiado para el caso de las regiones subdesarrolladas de Latinoamérica era precisamente "colonialismo interno", no "sociedades duales" (Stavenhagen, 1981: 21). Por su parte Gunder Frank cuestionaba la existencia de realidades que las expresiones de "sociedad dual” y “Tercer Mundo", aceptadas implícita o explícitamente en la academia, querían mostrar. Pensaba que la finalidad de hacerlas aparecer en el mundo eran "intentos para justificar y encubrir el imperialismo y/o revisionismo" (Gunder, 1973: 205). Ese cuestionamiento iba dirigido también contra el concepto de "colonialismo interno" de González Casanova. Gunder Frank afirmaba que el trabajo de González Casanova remitía a una "tesis burguesa” disfrazada que defendía el estado de cosas del momento.

No pocos lectores de aquellos años encontraron similares o ligadas al menos teóricamente las perspectivas de Gunder Frank y González Casanova sobre desarrollo, subdesarrollo y colonialismo interno. El primero rechazó que su trabajo tuviera que ver con el del segundo. La diferencia entre él y González Casanova - aseguraba - residía en que en sus trabajos el colonialismo interno no sustituía a la teoría de clases como lo hacía el autor de Sociología de la explotación (Gunder, 1973: 222). Partía del supuesto de que las colonias se incorporan al sistema capitalista mundial y nacional de forma desigual y contradictoria. Así, los indígenas marginados de los que habló el autor de La democracia en México (González, 1978) no estuvieron nunca en una economía de subsistencia, lo que sucedía era que cuando no les convenía no producían para el mercado. Pero su miseria se debía a que se integraban económicamente al sistema mundial y nacional en el que vivían desde la Conquista. El colonialismo interno que sufren - apuntaba Gunder Frank - era económico y no cultural o social, como creía González Casanova. Entonces, "el verdadero colonialismo interno" de Gunder Frank estaba estrechamente vinculado con el colonialismo externo o imperialismo (Gunder, 1973: 291).

Las críticas de Stavenhagen y Gunder Frank estaban en lo correcto en cuanto al uso del término de "sociedades duales". Aunque debe reconocerse que González Casanova pronto reparó en su error. Quizá el factor clave para entenderlo fue comprender que su conceptualización del colonialismo interno de los sesenta es cercana a un contenido étnico y cultural. Esto es, su énfasis sobre el colonialismo estaba impregnado de una antropología culturalista que daba mucho más peso a la desigualdad y la discriminación que a la dominación y la explotación. Aun con esta limitación, intuía que para el caso de México el problema indígena era un asunto de colonialismo interno: "Las comunidades indígenas son nuestras colonias internas" (González, 1978: 104), escribía, y las formas en que se ejerce este colonialismo radican principalmente en el intercambio comercial desfavorable para los indígenas, lo que provoca su dependencia económica, explotación combinada - "mezcla de feudalismo, capitalismo, esclavismo, trabajo asalariado y forzado, aparcería y peonaje" - por parte de la población ladina para con las comunidades indígenas, despojo de tierras, discriminación social y exclusión (González, 1978: 
106). En buena medida, estas formas de colonialismo interno eran descritas por los antropólogos mexicanos de la época de quienes González Casanova se nutría para hacer su análisis sociológico de la democracia en México. Sin embargo, la perspectiva cultural y humanista de la antropología mexicana sobre el problema indígena:

nunca tuvo un sentido anticolonialista, ni en las épocas más revolucionarias del país. Influida por la metodología de una ciencia que precisamente surgió en los países metropolitanos para el estudio y control de los habitantes de sus colonias, no pudo proponerse como tema central de estudio el problema del indígena como un problema colonial y como un problema eminentemente político (González, 1978: 122).

Esta perspectiva cultural del concepto de "colonialismo interno", ligada al tema de la "sociedad dual", cambió cuando González Casanova viró hacia el concepto de "explotación" a finales de la década de 1960. Sin considerarse marxista, redactó su So-

ciología de la explotación (González, 1969), texto en el que incluyó el tema del colonialismo interno con la intención de estimular el estudio del desarrollo del capitalismo en los países coloniales, pero cambió más profundamente cuando redefinió el concepto de "colonialismo interno". Aceptada esta crítica, sin embargo, resulta falsa la otra: querer sustituir el concepto de "clases sociales" por el de "colonialismo interno". La diferencia de González Casanova con Stavenhagen y Gunder Frank sobre el tema radicaba en que para el primero el colonialismo interno no sólo era una relación de dominio y explotación en un sentido marxista ortodoxo, sino una relación de dominio y explotación de una población por otra, con su dialéctica compleja - relación propietario y trabajador, discriminación cultural, exclusión política, etc. - al interior de cada una de ellas. Pero debe pensarse también a la inversa: González Casanova tampoco abandona la cuestión étnica y cultural por el concepto de lucha de clases o explotación. En una palabra: el abandono del término "sociedades duales” no significó terminar con su apuesta política desde La democracia en México sobre la inclusión de los indígenas y marginales al desarrollo del país y la cuestión nacional.

A propósito del concepto de "marginalidad", es muy probable que González Casanova lo integrara en su análisis debido al uso que se le daba en los años sesenta del siglo pasado. En principio se refería a "los sectores de población segregados en áreas no incorporadas al sistema de servicios urbanos en viviendas improvisadas y sobre terrenos ocupados ilegalmente" (Germani, 1973: 12). Luego el concepto se extendió a los sectores que no participaban en la vida política, sindical e institucional de una sociedad, por lo que resultaban excluidos y marginados del desarrollo nacional. Esta falta de identificación nacional fue también considerada un rasgo distintivo de la condición marginal, sobre todo en países en los que se diferenciaba a la población indígena que "no participaba" de los grupos que sí participaban en la vida nacional. La marginalidad se relacionó entonces con el colonialismo interno que explicaba no sólo la dominación económica y política de unos grupos por otros, sino también la "superposición cultural”. Este enfoque, habrá que aceptarlo, fue desarrollado por González Casanova.

\section{EL COLONIALISMO INTERNO COMO CATEGORÍA TABÚ Y SU REDEFINICIÓN}

Por lo que se ha dicho hasta aquí, es comprensible que para Pablo González Casanova el colonialismo interno se tornara en una categoría tabú en varios frentes: entre los ideólogos del imperialismo, los nacionalistas, la izquierda y los marxistas, incluso en los que todavía luchan por el socialismo. En los primeros es obvio: no pueden concebir que existan relaciones de desigualdad y explotación. Los nacionalistas y demás posiciones progresistas no se enteran de que en los Estados-nación se establecen estructuras coloniales y de que a veces dentro de las mismas organizaciones se presenta el fenómeno. González Casanova es enfático y dice: 
si, como afirmara Marx, "un país se enriquece a expensas de otro país" al igual que "una clase se enriquece a expensas de otra clase", en muchos Estados-nación que provienen de la conquista de territorios, llámense Imperios o Repúblicas, a esas dos formas de enriquecimiento se añaden las del colonialismo interno (González, 2006: 410).

González Casanova reconoce que los fenómenos de colonialismo interno ligados a la lucha por la liberación, la democracia y el socialismo aparecieron una vez que los movimientos de izquierda de los años setenta de siglo pasado cayeron en cuenta de las contradicciones en que habían incurrido los Estados, los movimientos sociales y las guerrillas dirigidos por los comunistas y los nacionalistas del llamado "Tercer Mundo": "Aún así, puede decirse que no fue sino hasta fines del siglo xx cuando los movimientos de resistencia y por la autonomía de las etnias y los pueblos oprimidos adquirieron una importancia mundial" (González, 2006: 411). Por esta razón, en pleno siglo xxi González Casanova redefinió el concepto de "colonialismo interno". Lo primero que hizo fue revisar algunas de las causas por las que éste se convirtió en tabú. Una de las tareas fue reavivar el "asunto nacional" - como se llamaba eufemísticamente al colonialismo interno en la Rusia soviética - que los rusos nunca acabaron de entender y sobre el que Lenin ya se había pronunciado. En la primera mitad del siglo $\mathrm{xx}$, fruto de la concepción marxista dogmática que imperaba, se hacía difícil encontrar la convergencia de la "revolución socialista" y la "revolución nacional”. Se precisaba la teoría de las clases, no así lo que podía hacerse desde el marxismo en torno a las etnias o las nacionalidades, sólo se concebían como sobredeterminaciones circunstanciales. Así:

los conceptos de etnias y nacionalidades, como los de alianzas y frentes, oscilaron más que los de la lucha de clases en función de categorías abstractas y posiciones tácticas. Clase y nación, socialismo y derechos de las etnias, enfrentamientos y alianzas, se defendieron por separado o se juntaron según los juicios coyunturales del partido sobre las "situaciones concretas" (González, 2006: 413).

Ése fue uno de los factores por los que en varias regiones del mundo, incluido México, el Partido Comunista y los movimientos guerrilleros y estudiantiles formados en este marxismo no lograron entender la lucha campesina e indígena radical que se gestó con mayor intensidad durante las décadas de los sesenta y setenta del siglo pasado. Pero también ésta fue una de las razones por las que en México no se comprendió a González Casanova en su libro $\mathrm{La}$ democracia en México, cuando insistía en que para transitar al socialismo se requería primero democratizar al país y resolver la tarea nacional, a saber, terminar con el marginalismo producto del colonialismo interno. En este contexto, el colonialismo interno como categoría fue objeto de no pocas reificaciones. González Casanova enumera cinco: 1) se le desligaba de las clases sociales e incluso se le excluía de las relaciones de explotación; 2) no se le asociaba con la lucha por el poder efectivo de un Estado-nación multiétnico; 3) se le relacionaba con el separatismo o tribalismo étnico; 4) se le hacía borroso en nombre de la lucha de clases, y 5) se le rechazaba con argumentos propios de la sociología, la antropología o la ciencia política estructuralfuncionalista para afirmar que se trataba de un problema eminentemente cultural (González, 2006: 417).

En la primera y la segunda mistificaciones no se entiende que el concepto explica un fenómeno propio del capitalismo. El sociólogo marxista de los años setenta tampoco se percata con esta ceguera a cuestas de los sujetos que luchan contra este sistema: los indígenas, parte del pueblo trabajador y del movimiento por la democracia, la liberación y el socialismo. Al perder de vista este aspecto de la lucha contra el capitalismo, quienes aspiran al poder de un Estado que sea de todo el pueblo o de todos los pueblos dejan de lado el poder alternativo socialista que representan las etnias colonizadas una vez que 
se han radicalizado en su lucha. La tercera mistificación se relaciona con el llamado "etnicismo", el batustanismo y otras formas de balcanización que han sido favorables para las políticas racistas y coloniales de los países con esta mirada. Esta "versión conservadora del colonialismo interno niega u oculta la lucha de clases y la lucha antiimperialista, aísla a cada etnia y exalta su identidad como una forma de aumentar su aislamiento" (González, 2006: 417). En la cuarta reificación del concepto se piensa en la historia de manera lineal. Si en Europa se luchó contra el feudalismo para que las contradicciones del capitalismo aparecieran una vez nacido éste, esta ley de la historia se repetiría en todas las regiones del mundo. Por tal razón "se rechaza al colonialismo interno en nombre de la 'necesaria descampesinización' y de una supuesta tendencia a la proletarización de carácter determinista, que idealiza a una lucha de clases simple" (González, 2006: 417). ${ }^{3}$

La última reificación es aquella en la que el propio González Casanova incurrió. Con argumentos de la

original, el cual mostró como inicio en Sociología de la explotación, conjugado con las críticas a su pensamiento de aquellos años y los acontecimientos importantes de México y América Latina -movimientos campesinos y guerrilleros, la Revolución cubana, el movimiento estudiantil de 1968-, lo llevaron a pensar más en términos de explotación que de poder. En suma, al rechazar el tabú hacia el concepto de "colonialismo interno" y al redefinirlo con base en nuevos enfoques, González Casanova, a diferencia de otros pensadores latinoamericanos, siguió con la idea de usar el potencial explicativo y político del concepto para luchar en el terreno de las ideas, al lado de proletarios, colonizados, excluidos, ciudadanos, estudiantes, indígenas y todos los pobres de la tierra por un régimen que construya la democracia, la liberación y el socialismo. Con este enfoque abierto, crítico y flexible del colonialismo interno, el autor también se inclinará hacia los grupos sociales emergentes, contrahegemónicos y anticapitalistas que en plena globalización incorporará a sus análisis.

ta, quería llegar a la conclusión de que el colonialismo interno era producto de la llamada "sociedad tradicional" o "sociedad dual". Este mal se ataca, según esta versión, por medio de la modernización del país y la integración de la nación a los grupos marginados. Así, para llegar al progreso se requiere un Estado de derecho en el que todos los ciudadanos sean iguales ante la ley. En buena medida, lo que le permitió a González Casanova redefinir el concepto de "colonialismo interno" fue su tránsito intelectual. El viraje de un nacionalismo revolucionario con el que se identificaba todavía en La democracia en México hacia un marxismo heterodoxo muy

\footnotetext{
${ }^{3}$ En la actualidad sucede lo mismo con el concepto de "clase". Producto de la llamada crisis del marxismo, pocos lo utilizan. Ahora se quiere volver al asunto campesino y étnico, aunque sin la categoría de clase. Armando Bartra (2010) repara sobre este nuevo fenómeno y advierte que es fundamental seguirlo pensando, pero de manera flexible para enriquecerlo. También insiste en reflexionar sobre la presencia de lo indio y lo campesino en América Latina.
}

\section{LA DEMOCRACIA UNIVERSAL FRENTE AL COLONIALISMO Y LA EXPLOTACIÓN GLOBAL}

La característica que distingue a Pablo González Casanova de otros pensadores, científicos sociales e intelectuales de México y América Latina no sólo radica en evitar seguir las modas académicas o caminar al lado de príncipe, la central es que jamás renuncia a un tipo de pensamiento sin antes revisar los fundamentos, categorías, errores y posibles replanteamientos que pudieran explicar mejor la realidad. Eso ha hecho con las tres categorías base que nutren su pensamiento desde su edad temprana como intelectual: la democracia, el colonialismo interno y la explotación. ${ }^{4}$ En el nuevo ciclo histórico

\footnotetext{
${ }^{4}$ Para un estudio detenido sobre la vida y obra de Pablo González Casanova véase Torres (2012).
} 
que se ha denominado neoliberalismo y globalización, Pablo González Casanova piensa la democracia universal. Subsume en este nuevo concepto las luchas nacionales, culturales, marxistas, étnicas, obreras, socialistas y alternativas con la intención de replantear el esquema teórico que lo había guiado durante casi un siglo. Hizo este replanteamiento teórico también con los conceptos de explotación y colonialismo interno. El punto de partida fue el nuevo modo de pensar la democracia. Si en estos tiempos ha de pensarse de manera universal y plural, es porque la explotación y el colonialismo ahora son globales. Después consideró que para que siga siendo dialéctica la mirada sobre la explotación y el colonialismo global debería tener un enfoque diferente y estar situada en el "Tercer Mundo", esto es, en el sur del planeta (González, 1990). La mirada política desde el sur es siempre con democracia y liberación de los pobres.

Posteriormente, amplió esta perspectiva al lado de Samir Amin. Pablo González Casanova coordinó el segundo volumen de La nueva organización capitalista mundial vista desde el sur (Amin y González, 1995 y 1996). Ahí replanteó su concepto de colonialismo bajo el nuevo sello histórico del neoliberalismo y la globalización. Lo hizo sin perder de vista sus otras categorías eje: la democracia y la explotación. En el nuevo escenario de la explotación global, González Casanova exploró el contexto mundial. Le preocupaba la soberanía de los pueblos. Habló del "Tercer Mundo" como un mundo colonial renovado. Advirtió que la llamada democracia occidental había mostrado ya sus límites. Estaba persuadido de que:

el estudio del contexto mundial al fin de la guerra fría revela además la necesidad de regímenes con poder de los pueblos y con democracia plural de los ciudadanos, una especie de paradigmas alternativos cuyo carácter emergente apenas se esboza en algunas regiones del Tercer Mundo (González, 1996: 12).

Colocó su reflexión por encima de la disyuntiva socialismo o capitalismo. Reflexionó sobre las lecciones que la historia ha mostrado en la experiencia del llamado "socialismo real" y el nuevo capitalismo global. Precisamente por ello, para quienes creen que el "Tercer Mundo" es un concepto anticuado, González Casanova sugirió que ahora era más adecuado que nunca. Su principio es elemental: si "Tercer Mundo" quiere decir pueblos sujetos a dominación, relaciones coloniales y explotación, aunque se exclame que el muro de Berlín ya cayó, en Asia, América Latina y África sigue habiendo pueblos coloniales. El "Tercer Mundo" incluye al exbloque soviético, China, el interior de Estados Unidos, Europa y Japón. Pablo González Casanova no identifica la explotación sólo con el concepto de plusvalía arrancada a los trabajadores, desde luego que acepta esa relación, la explicó en su Sociología de la explotación. La identifica además, y aquí está lo novedoso de su categoría, con fenómenos de parasitismo y de lo que en biología se llaman “colonias". Los fenómenos que en biología se conocen como coevolución y depredación se replican en la especie humana cuando unos sujetos privan a otros de sus recursos de vida. En la historia humana han existido distintas formas de explotación: tributarias, esclavistas, feudales, asalariadas, colonialistas. Es vergonzoso - exclama nuestro intelectual- que los científicos nieguen la explotación como central en la historia de la vida humana. En el mundo en que vivimos, un grupo pequeño de parásitos se enriquece a costa de la gran mayoría de la población (González, 1999: 73).

Para González Casanova las fuerzas populares que luchen en esta nueva era de globalización se enfrentarán a la violencia del terrorismo civil y de Estado, al narcotráfico, al deterioro de la naturaleza, a la crisis financiera, a las desigualdades tecnológicas y a la falta de democracia. Además, tendrán que enfrentarse a un fenómeno nuevo: el colonialismo global. Este nuevo tipo de relación asimétrica tiene como objetivo atacar los sistemas de alimentación, salud y educación de los pueblos, también desprestigiar las revoluciones y las insurgencias populares. Vende la apariencia de que la democracia 
occidental es la única alternativa al humanismo y el desarrollo económico. Visto de esta manera, todas las intervenciones extranjeras a los pueblos son legítimas. En este tenor, con el neoliberalismo los elementos para el desarrollo tienden a estar separados. Por ejemplo, la economía se entiende como una fuerza autónoma que no se vincula con las necesidades de la población. El Estado no cumple una función social, sino de control y represión de la política de oposición. La sociedad civil se mantiene a raya a fin de evitar su empoderamiento y la creación de alternativas. Los agravios a la sociedad se cometen en contra de sectores separados: obreros, campesinos, estudiantes, clase media, etcétera, de esta manera las víctimas no se enfrentan en unidad a la ofensiva contrarrevolucionaria. Por ello el sociólogo mexicano cree que los dominados deben pensar en una lucha nueva y creativa que combine presión y negociación, acción transformadora y aceptación de reformas o pactos sociales que beneficien parcialmente a los pueblos. Para él:

hoy son revolucionarios, o son concebidos como revolucionarios, movimientos que no venden o abandonan su lógica de mayorías, aunque entre sus proyectos no privilegien la toma del poder por la fuerza, sino más bien una política de acumulación de fuerza que reclama espacios de acción legal (González, 1996: 52).

A decir de González Casanova la supervivencia del mundo tendrá su punto de partida en la democracia universal y de todos, en especial la democracia de "los de abajo".

La democracia de los de abajo o "democracia de los pobres", tiene un carácter político y un carácter heurístico, que es necesario distinguir [...] Por democracia de los pobres se entiende aquí la búsqueda de la democracia en sus organizaciones y no una democracia en que los pobres sean eternamente pobres (González, 1996: 119, 121).

Así, el primer problema de esta democracia es la seguridad, es decir, cómo evitar la violencia de los enemigos y cómo solucionar la economía, la cultura, la comunicación o la acumulación teórica que dé sobrevivencia al movimiento. En otras palabras, la democracia de los pobres de la tierra debe atender puntos básicos para que no sea doblegada fácilmente. En primer lugar está la seguridad económica, las economías de resistencia. Se trata de crear sistemas de producción, intercambio, consumo, fondos de ahorro y solidaridad entre los pueblos que permitan mantener firme la lucha sin claudicar a la cooptación por hambre o seguridad social. Para esto es indispensable hacer ciencia económica desde los pobres, conocer con precisión los movimientos y dinámicas de la economía transnacional y sus fuerzas asociadas que buscarán "boicot o bloqueos" a los mercados alternativos de las comunidades democráticas. En segundo lugar se requiere una política de unidad: "Los pobres - en la aldea, la nación o el mundo- necesitan una democracia que no los divida, que les permita juntar fuerzas y no caer en enfrentamientos, odios, fobias y persecuciones de pobres contra pobres" (González, 1996: 125). La política de unidad pasa por reconocer la diversidad, el pluralismo ideológico, religioso o cultural. Lo que los hombres hagan y piensen, sean de tal color, credo religioso o ideología, no debe ser el punto de discordia sino de unidad. La democracia plural permite acumular fuerzas, experiencias y enriquece la lucha de manera creativa. Para lograr esto González Casanova piensa que se necesitará una pedagogía de la tolerancia basada en la crítica a las distintas formas de enajenación que generan fragmentación racial, religiosa, cultural e incluso de clase.

Desde esta óptica, cualquier movimiento alternativo de hoy que no se plantee el colonialismo interno y su relación con el colonialismo global está destinado a comprender muy poco de lo que se teje en la nueva ofensiva capitalista y neoliberal. Quizá por eso las nuevas fuerzas emergentes, como él les llama, han replanteado la democracia, la liberación y el socialismo. Esto es muy nuevo, sobre todo porque la lógica de la lucha política cambia: se centra en fortalecer a la sociedad civil frente al Estado, en 
robustecer los valores ético-políticos de las comunidades y las organizaciones autónomas de la resistencia frente al capitalismo. En la actualidad, no son pocos los movimientos sociales que han reivindicado conceptos como "respeto", "dignidad", "autonomía,, "poder alternativo", "redes sociales", en particular los pueblos indios, que fueron capaces de evidenciar en su lucha las distintas formas de opresión, discriminación y explotación, derivadas en buena medida del colonialismo interno y global. Desde este escenario el autor advierte que la lucha por la democracia de las organizaciones de los de abajo parece prioritaria, por lo que habría que combinarla con otras luchas y otros frentes: en la sociedad civil y el pueblo, en el sistema político, en la democratización del poder del Estado, a nivel nacional o interno, internacional, transnacional y universal (González, 1996: 133). Al lado de esta prioridad se requiere, entre otras cosas, pensar analítica y políticamente los conceptos de "explotación", "democracia" y "colonialismo" en sus dimensiones interna y global.

\section{PALABRAS FINALES}

Reconocer el mérito de Pablo González Casanova de haber incluido en el campo de las ciencias sociales, sobre todo para entender fenómenos de exclusión, invisibilización y resistencia popular, la categoría de colonialismo interno fue uno de los objetivos de este trabajo. En tal objetivo se integró una tesis: que el potencial analítico y político de dicha categoría es vigente. Por otro lado, mostramos una característica de la veta intelectual de González Casanova: la crítica y la autocrítica. En concreto, recibió cuestionamientos a su manera de entender el colonialismo interno que con el tiempo y los cambios históricos lo llevaron a redefinirlo. En este mismo tenor, González Casanova tiene otra característica que lo distingue como intelectual: llevar la ciencia a las humanidades y a la política. Eso hizo con el concepto de "colonialismo interno" que incluyó en su trabajo científico, la idea era encontrar su potencial explicativo para trasladarlo al terreno de la lucha ideológica al lado de los pobres de la tierra. Para esto une su idea del colonialismo interno con los conceptos de "explotación" y "democracia universal", esto es, "la democracia de todos" sin exclusiones ni excluidos.

Ante los nuevos escenarios mundiales de colonialismo y explotación, González Casanova piensa en una democracia no excluyente, universal, con connotaciones morales y prácticas, humanísticas y científicas, utópicas y políticas. Es interesante que a pesar de todo lo sucedido después de 1989 el autor siga sosteniendo que los protagonistas de los intereses generales son los movimientos particulares de los oprimidos. Para él, explotados, reprimidos, marginados, excluidos y pobres de la tierra son quienes pueden universalizar la democracia. Van convirtiendo sus demandas en un principio particulares -alimento, vestido, casa, salud, educación, etcéteraen demandas más universales y complejas: democracia, derechos, justicia, paz con dignidad. Pablo González Casanova consideró que esto era posible por lo menos desde 1965, cuando publicó La democracia en México. En 1994 se percató con sus propios ojos y en su propio país de que tenía razón. En un pequeño rincón del mundo conocido como $\mathrm{La}$ Lacandona, un movimiento armado de indios mexicanos planteaba un nuevo proyecto de "democracia universal" y demandaba el fin de las distintas formas de colonialismo, exclusión y explotación contra los pueblos indígenas del mundo. Ese año, inesperadamente, González Casanova se había topado con uno de esos sujetos colectivos sobre los que había teorizado durante más de medio siglo: el Ejército Zapatista de Liberación Nacional.

\section{BIBLIOGRAFÍA}

Amin, Samir y Pablo González Casanova (dirs.), 1995, La nueva organización capitalista mundial vista desde el sur, vol. I: Mundialización y acumulación, Anthropos, Centro de Investigaciones Interdisciplinarias en Cien- 
cias y Humanidades-Universidad Nacional Autónoma de México, Barcelona.

-, 1996, La nueva organización capitalista mundial vista desde el sur, vol. II: El Estado y la política en el sur del mundo, Anthropos, Centro de Investigaciones Interdisciplinarias en Ciencias y Humanidades-Universidad Nacional Autónoma de México, Barcelona.

Bartra, Armando, 2010, "Campesindios. Aproximaciones a los campesinos de un continente colonizado", en Memoria, Revista de Política y Cultura, Centro de Estudios del Movimiento Obrero y Socialista, núm. 248, pp. 4-13.

Chaloult, Yves, 1978, Estado, acumulacão e colonialismo interno: contradições nordeste/sudeste, 1960-1977, Editôra Vozes, Petrópolis.

Drakakis-Smith, David y Stephen Wyn Williams (eds.), 1983, Internal Colonialism: Essays around a Theme, Department of Geography-University of Edinburgh, Edimburgo.

Falcón, Romana, 2002, México descalzo. Estrategias de sobrevivencia frente a la modernidad liberal, Plaza y Janés, México.

Germani, Gino, 1973, El concepto de marginalidad, Nueva Visión, Buenos Aires.

González Casanova, Pablo, 1963a, "Sociedad plural, colonialismo interno y desarrollo", en América Latina, año 6, núm. 3, Centro Latinoamericano de Investigaciones en Ciencias Sociales, Río de Janeiro, pp. 15-32.

— , 1963b, "México: desarrollo y subdesarrollo", en Desarrollo Económico, vol. 3, núms. 1 y 2, pp. 285-301.

—, 1969, Sociología de la explotación, Siglo XXI, México.

- 1978, La democracia en México, Era, México.

, 1990, "El socialismo como alternativa global (una perspectiva del sur)", en La Jornada, 1 y 2 de diciembre.

__ 1996, "El colonialismo global y la democracia", en Samir Amin y Pablo González Casanova (dirs.), La nueva organización capitalista mundial vista desde el sur, vol. II: El Estado y la política en el sur del mundo, Anthropos, Centro de Investigaciones Interdisciplinarias en Ciencias y Humanidades-Universidad Nacional Autónoma de México, Barcelona.

— , 1998, "La democracia de todos", en Emir Sader (ed.), Democracia sin exclusiones ni excluidos, Asociación Latinoamericana de Sociología, Consejo Latinoamericano de Ciencias Sociales, Organización de las Naciones Unidas para la Educación, la Ciencia y la Cultura, Nueva Sociedad, Venezuela.

— , 1999, “La explotación global”, en Ricardo Valero (coord.), Globalidad: una mirada alternativa, Miguel Ángel Porrúa, Centro Latinoamericano de la Globalidad, México.

— , 2006, "El colonialismo interno: una redefinición”, en Atilio A. Boron, Javier Amadeo y Sabrina González (comps.), La teoría marxista hoy: problemas y perspectivas, Consejo Latinoamericano de Ciencias Sociales, Buenos Aires.

Gunder Frank, André, 1973, América Latina: subdesarrollo y revolución, Era, México.

Hechter, Michael, 1975, Internal Colonialism: The Celtic Fringe in British National Development, Routledge \& Kegan Paul, Londres.

Hicks, Jack, 2004, "On the Application of Theories of 'Internal Colonialism' to Inuit Societies”, presentación, Annual Conference of the Canadian Political Science Association, Winnipeg, 5 de junio, en línea: <http://www. cpsa-acsp.ca/papers-2004/Hicks.pdf>.

Huerta Preciado, María Teresa, 1976, Rebeliones indígenas de la época colonial, Instituto Nacional de Antropología e Historia, México.

Katz, Friedrich (comp.), 1990, Revuelta, rebelión y revolución. La lucha rural en México del siglo XVI al siglo $\mathrm{XX}$, Era, México.

Kahl, Joseph A., 1986, Tres sociólogos latinoamericanos, Escuela Nacional de Estudios Profesionales AcatlánUniversidad Nacional Autónoma de México, México.

Lambert, Jacques, 1978, América Latina. Estructuras sociales e instituciones políticas, Ariel, Barcelona.

Mallon, Florencia E., 2003, Campesino y nación. La construcción de México y Perú poscoloniales, El Colegio de San Luis, El Colegio de Michoacán, Centro de Investigaciones y Estudios Superiores en Antropología Social, México.

Mirafuentes Galván, José Luis, 1989, Movimientos de resistencia y rebeliones indígenas en el norte de México: 1680-1821. Guía documental, Instituto de Investigaciones Históricas-Universidad Nacional Autónoma de México, México.

Reina, Leticia, 1986, Las rebeliones campesinas en México: 1819-1906, Siglo XXI, México.

Rivera Cusicanqui, Silvia, 2010, Ch'ixinakax utxiwa: una reflexión sobre prácticas y discursos descolonizadores, Tinta Limón, Buenos Aires.

Stavenhagen, Rodolfo, 1963, "Clases, colonialismo y aculturación. Ensayo sobre un sistema de relaciones interétnicas en Mesoamérica”, en América Latina. Revista del Centro Latinoamericano de Investigaciones en Ciencias Sociales, año VI, núm. 4, Río de Janeiro.

— 1981, "Siete tesis equivocadas sobre América Latina”, en Sociología y subdesarrollo, Nuestro Tiempo, México.

Torres Guillén, Jaime, 2012, “Dialéctica de la imaginación: Pablo González Casanova, una biografía intelectual”, tesis de doctorado, Centro de Investigaciones y Estudios Superiores en Antropología Social, México.

Van Young, Eric, 2006, La otra rebelión. La lucha por la independencia de México, 1810-1821, Fondo de Cultura Económica, México. 